\title{
KESTABILAN PERSAMAAN FUNGSIONAL JENSEN
}

\author{
${ }^{1}$ Hilwin Nisa', ${ }^{2}$ Hairur Rahman, ${ }^{3}$ Imam Sujarwo \\ ${ }^{1}$ Jurusan Matematika, Universitas Islam Negeri Maulana Malik Ibrahim Malang \\ 2jurusan Matematika, Universitas Islam Negeri Maulana Malik Ibrahim Malang \\ 3jurusan Matematika, Universitas Islam Negeri Maulana Malik Ibrahim Malang
}

Email: azzami09hadza@gmail.com

\begin{abstract}
ABSTRAK
Persamaan fungsional Jensen merupakan variasi dari persamaan fungsional Cauchy additive yang paling sederhana dan paling bagus. Persamaan fungsional Jensen dapat diaplikasikan sebagai model dari suatu proses fisik ketika persamaan fungsional Jensen tersebut stabil. Oleh karena itu, dengan diketahuinya kestabilan dari persamaan fungsional tersebut, dapat menambah referensi para peneliti lain yang akan mengaplikasikan persamaan fungsional Jensen. Pada artikel ini akan ditunjukkan kestabilan persamaan fungsional Jensen. Untuk mengetahui kestabilannya digunakan teorema kestabilan Hyers-Ulam-Rassias. Berdasarkan hasil analisis, telah dibuktikan bahwa persamaan fungsional Jensen telah memenuhi teorema kestabilan Hyers-Ulam-Rassias, sehingga dapat dikatakan bahwa persamaan fungsional Jensen tersebut stabil.
\end{abstract}

Kata kunci: persamaan fungsional Cauchy additive, persamaan fungsional Jensen, kestabilan Hyers-UlamRassias

\begin{abstract}
Jensen functional equation is the simplest and the most elegant one among variations of Cauchy additive functional equation. Jensen functional equation can be applied as a model of physical process when it is stable. This article showed stability of Jensen functional equation. To know the stability, we used Hyers-Ulam-Rassias stability theorem. Based on the analysis, we proved that Jensen functional equation satisfy Hyers-Ulam-Rassias stability theorem, so it can be said that Jensen functional equation is stable.
\end{abstract}

Keywords: additive Cauchy functional equation, Jensen functional equation, Hyers-Ulam-Rassiass stability

\section{PENDAHULUAN}

Persamaan fungsional merupakan salah satu pembahasan dari matematika modern. Di antara berbagai macam persamaan fungsional, persamaan fungsional yang paling penting adalah persamaan fungsional Cauchy additive. Hal ini dikarenakan sifat-sifat dari persamaan fungsional Cauchy additive dapat digunakan untuk mengembangkan teorema-teorema dari persamaan fungsional lain. Ada banyak variasi dari persamaan fungsional Cauchy additive, akan tetapi diantara variasi persamaan fungsional Cauchy additive tersebut yang paling bagus dan paling sederhana adalah persamaan fungsional Jensen.

Suatu fungsi $f: \mathbb{R} \rightarrow \mathbb{R}$ disebut sebagai persamaan fungsional Jensen jika memenuhi $f\left(\frac{x+y}{2}\right)=$ $\frac{f(x)+f(y)}{2}, \forall x, y \in \mathbb{R}$. Persamaan fungsional Jensen dapat diaplikasikan sebagai model dari suatu proses fisik ketika persamaan fungsional Jensen tersebut stabil. Dengan diketahuinya kestabilan dari persamaan fungsional Jensen, akan dapat dijadikan referensi para peneliti lain yang bermaksud untuk mengaplikasikan persamaan fungsional Jensen tersebut.

Adapun konsep kestabilan yang digunakan untuk meneliti kestabilan persamaan fungsional Jensen pada artikel ini adalah konsep kestabilan HyersUlam-Rassias. Dalam teorema kestabilan HyersUlam-Rassias, persamaan fungsional yang dijadikan acuan adalah persamaan fungsional Cauchy additive. Jika yang diteliti kestabilannya adalah persamaan fungsional lain, maka persamaan fungsional Cauchy additive dalam teorema kestabilan Hyers-Ulam-Rassias diganti dengan persamaan fungsional tersebut. Oleh karena itu, untuk meneliti kestabilan persamaan fungsional Jesnen, persamaan fungsional Cauchy additive dalam teorema kestabilan Hyerss-Ulam-Rassias tersebut diganti dengan persamaan fungsional Jensen.

Artikel ini merupakan upaya ilmiah untuk meneliti kestabilan dari persamaan fungsional Jensen dalam rangka penelitian pengembangan. Pada peneltian ini dilakukan pembuktian terhadap teorema kestabilan Hyers-Ulam-Rassiass pada persamaan fungsional Jensen. Jika persamaan fungsional Jensen 
memenuhi teorema kestabilan Hyers-UlamRassiass, maka dapat dikatakan bahwa persamaan fungsional Jensen tersebut stabil.

\section{KAJIAN TEORI}

\section{Persamaan Fungsional}

Persamaan fungsional adalah persamaan fungsi yang belum diketahui fungsinya [1].

\section{Persamaan Fungsional Cauchy Additive}

Suatu fungsi $f: \mathbb{R} \rightarrow \mathbb{R}$ dikatakan suatu fungsi additive jika fungsi tersebut memenuhi persamaan fungsional Cauchy additive

$$
f(x+y)=f(x)+f(y)
$$

Untuk setiap $x, y \in \mathbb{R}[1]$.

\section{Persamaann Fungsional Jensen}

Suatu fungsi $f: \mathbb{R} \rightarrow \mathbb{R}$ disebut persamaan Jensen, jika persamaan tersebut memenuhi

$$
f\left(\frac{x+y}{2}\right)=\frac{f(x)+f(y)}{2}
$$

$\forall x, y \in \mathbb{R}[1]$

\section{Ruang Bernorma}

Misalkan $E$ suatu ruang vektor. Suatu pemetaan $\|\|:. E \rightarrow \mathbb{R}$ disebut norm, jika $\forall x, y \in E$ dan $\lambda \in \mathbb{R}$ berlaku

1. $\|x\| \geq 0$;

2. $\|x\|=0 \leftrightarrow x=0$;

3. $\|\lambda x\|=|\lambda|\|x\|$;

4. $\|x+y\| \leq\|x\|+\|y\|$.

(E, $\|\|$.$) disebut ruang vektor bernorma dan \|x\|$ disebut norm dari $x$ [2].

Setiap ruang bernorma $(K, \|$. $\|)$ merupakan ruang metrik terhadap $d$ :

$$
d(x, y)=\|x-y\|
$$

untuk setiap $x, y \in K[3]$.

\section{Barisan Konvergen}

Suatu barisan $X=\left\{x_{n}\right\} \in \mathbb{R}$ dikatakan konvergen ke $x \in \mathbb{R}$ atau $x$ dikatakan suatu limit dari $\left\{x_{n}\right\}$, jika untuk setiap $\varepsilon>0$ terdapat suatu bilangan asli $K(\varepsilon)$ sedemikian hingga untuk setiap $n \geq K(\varepsilon), x_{n}$ memenuhi $\left|x-x_{n}\right|<\varepsilon[4]$.

\section{Barisan Cauchy}

Suatu barisan $X=\left\{x_{n}\right\} \in \mathbb{R}$ dikatakan suatu barisan Cauchy jika untuk setiap $\varepsilon>0$ terdapat suatu bilangan asli $H(\varepsilon)$ sedemikian hingga untuk setiap bilangan asli $n, m \geq H(\varepsilon), x_{n}$ dan $x_{m}$ memenuhi $\left|x_{n}-x_{m}\right|<\varepsilon[4]$.

Di dalam sembarang ruang metrik $(X, d)$ setiap barisan konvergen merupakan barisan Cauchy [5].

\section{Ruang Banach}

Ruang Banach merupakan ruang bernorma yang lengkap [6]. Ruang bernorma dikatakan lengkap jika setiap barisan Cauchy-nya konvergen [2].

\section{Kestabilan Hyers-Ulam-Rassiass}

Misalkan $E_{1}$ dan $E_{2}$ merupakan ruang Banach, dan misalkan $f: E_{1} \rightarrow E_{2}$ suatu fungsi yang memenuhi pertidaksamaan

$$
\|f(x+y)-f(x)-f(y)\| \leq \theta\left(\|x\|^{p}+\|y\|^{p}\right)
$$

untuk $\theta>0, p \in[0,1)$, dan $\forall x, y \in E_{1}$. Maka ada $A: E_{1} \rightarrow E_{2}$ suatu fungsi additive yang tunggal, sedemikian hingga

$\forall x \in E_{1}[7]$.

$$
\|f(x)-A(x)\| \leq \frac{2 \theta}{2-2^{p}}\|x\|^{p}
$$

\section{PEMBAHASAN}

Untuk membuktikan kestabilan persamaan fungsional Jensen dengan menggunakan konsep kestabilan Hyers-Ulam-Rassias, maka persamaan fungsional Cauchy additive dalam teorema kestabilan Hyers-Ulam-Rassias tersebut diganti dengan persamaan fungsional Jensen. Oleh karena itu, untuk meneliti kestabilan persamaan fungsional Jensen adalah dengan membuktikan teorema berikut ini:

Misalkan $f: E_{1} \rightarrow E_{2}$ merupakan suatu fungsi antara ruang Banach. Jika $f$ memenuhi pertidaksamaan fungsional

$\left\|2 f\left(\frac{x+y}{2}\right)-f(x)-f(y)\right\| \leq \theta\left(\|x\|^{p}+\|y\|^{p}\right) \ldots(1)$ $\forall \theta \geq 0$, dengan $0 \leq p<1$ dan $\forall x, y \in$ $E_{1}$ ada $A: E_{1} \rightarrow E_{2}$, suatu fungsi additive yang tunggal, sedemikian hingga

$\forall x \in E_{1}$.

$$
\|f(x)-A(x)\| \leq \frac{2 \theta}{2-2^{p}}\|x\|^{p}
$$

\section{Bukti:}

Karena fungsi tersebut terjadi di antara ruang Banach $\left(E_{1}\right.$ dan $\left.E_{2}\right)$ dan $\forall x, y \in E_{1}$, dan karena ruang Banach merupakan ruang bernorma yang lengkap, maka akan berlaku sifat dari ruang bernorma sebagi berikut:

1. $\|x\| \geq 0$;

2. $\|x\|=0 \leftrightarrow x=0$; 
3. $\|\lambda x\|=|\lambda|\|x\|$, dimana $\lambda \in \mathbb{R}$;

4. $\|x+y\| \leq\|x\|+\|y\|$.

Untuk membuktikan teorema Hyers-Ulam-Rassias, maka harus ditunjukkan bahwa:

1. $\left\{\frac{f\left(2^{n} x\right)}{2^{n}}\right\}_{n=1}^{\infty}$ merupakan suatu barisan Cauchy untuk setiap $x \in E_{1}$.

2. Jika $A(x)=\lim _{n \rightarrow \infty} \frac{f\left(2^{n} x\right)}{2^{n}}$, maka $A$ merupakan fungsi additive.

3. A memenuhi $\|f(x)-A(x)\| \leq \frac{2 \theta}{2-2^{p}}\|x\|^{p}, \forall x \in$ $E_{1}$.

4. A merupakan fungsi yang tunggal.

Asumsikan $f(0)=0$,

$\left\|2 f\left(\frac{x+y}{2}\right)-f(x)-f(y)\right\| \leq \theta\left(\|x\|^{p}+\|y\|^{p}\right)$.

Jika diambil $y=0$ dan $f(0)=0$, maka

$$
\begin{gathered}
\left\|2 f\left(\frac{x+0}{2}\right)-f(x)-f(0)\right\| \\
\leq \theta\left(\|x\|^{p}+\|0\|^{p}\right) \\
\left\|2 f\left(\frac{x}{2}\right)-f(x)\right\| \leq \theta\left(\|x\|^{p}\right) .
\end{gathered}
$$

Dengan mengganti $x=2 x$ dan kedua sisi dibagi dengan 2, maka akan diperoleh

$$
\left\|f(x)-\frac{1}{2} f(2 x)\right\| \leq \frac{\theta}{2}\left(\|2 x\|^{p}\right), \forall x \in E_{1} .
$$

Misalkan $n, m$ bilangan bulat nonnegatif dengan $n<$ $m$, maka

$$
=\left\|\begin{array}{c}
\left\|\frac{1}{2^{n}} f\left(2^{n} x\right)-\frac{1}{2^{m}} f\left(2^{m} x\right)\right\| \\
\frac{1}{2^{n}} f\left(2^{n} x\right)-\frac{1}{2^{n+1}} f\left(2^{n+1} x\right) \\
+\frac{1}{2^{n+1}} f\left(2^{n+1} x\right) \\
-\frac{1}{2^{n+2}} f\left(2^{n+2} x\right)+\cdots+\frac{1}{2^{m-1}} f\left(2^{m-1} x\right) \\
-\frac{1}{2^{m}} f\left(2^{m} x\right)
\end{array}\right\| .
$$

Karena $f$ suatu fungsi di antara ruang Banach, dengan menggunakan sifat keempat pada ruang bernorma (ketaksamaan segitiga), maka diperoleh

$$
\begin{aligned}
& \left\|\frac{1}{2^{n}} f\left(2^{n} x\right)-\frac{1}{2^{m}} f\left(2^{m} x\right)\right\| \\
& \leq\left\|\frac{1}{2^{n}} f\left(2^{n} x\right)-\frac{1}{2^{n+1}} f\left(2^{n+1} x\right)\right\| \\
& +\| \frac{1}{2^{n+1}} f\left(2^{n+1} x\right) \\
& -\frac{1}{2^{n+2}} f\left(2^{n+2} x\right) \|+\cdots \\
& +\left\|\frac{1}{2^{m-1}} f\left(2^{m-1} x\right)-\frac{1}{2^{m}} f\left(2^{m} x\right)\right\| \\
& =\frac{1}{2^{n}}\left\|f\left(2^{n} x\right)-\frac{1}{2^{n}} f\left(2^{n+1} x\right)\right\| \\
& +\frac{1}{2^{n+1}} \| f\left(2^{n+1} x\right) \\
& -\frac{1}{2^{n}} f\left(2^{n+2} x\right) \|+\cdots \\
& +\frac{1}{2^{m-1}}\left\|f\left(2^{m-1} x\right)-\frac{1}{2^{m}} f\left(2^{m} x\right)\right\|
\end{aligned}
$$

$$
\begin{aligned}
& \leq \frac{1}{2^{n}} \frac{\theta}{2}\left(\left\|2^{n+1} x\right\|^{p}\right)+\frac{1}{2^{n+1}} \frac{\theta}{2}\left(\left\|2^{n+2} x\right\|^{p}\right) \\
& \quad+\cdots+\frac{1}{2^{m-1}} \frac{\theta}{2}\left(\left\|2^{m} x\right\|^{p}\right) \\
& =\frac{2^{p}}{2^{n}} \frac{\theta}{2}\left(\left\|2^{n} x\right\|^{p}\right) \\
& +\frac{2^{p}}{2^{n+1}} \frac{\theta}{2}\left(\left\|2^{n+1} x\right\|^{p}\right)+\cdots \\
& +\frac{2^{p}}{2^{m-1}} \frac{\theta}{2}\left(\left\|2^{m-1} x\right\|^{p}\right) \\
& =\frac{2^{p} \theta}{2}\left(\|x\|^{p}\right)\left(\frac{2^{p n}}{2^{n}}+\frac{2^{p(n+1)}}{2^{n+1}}+\cdots+\frac{2^{p(m-1)}}{2^{m-1}}\right) \\
& =\frac{2^{p} \theta}{2}\left(\|x\|^{p}\right) \sum_{k=n}^{m-1} \frac{2^{k p}}{2^{k}} .
\end{aligned}
$$

Jadi,

$$
\left\|\frac{1}{2^{n}} f\left(2^{n} x\right)-\frac{1}{2^{m}} f\left(2^{m} x\right)\right\| \leq \frac{2^{p} \theta}{2}\left(\|x\|^{p}\right) \sum_{k=n}^{m-1} \frac{2^{k p}}{2^{k}} .
$$

Berdasarkan definisi barisan Cauchy, barisan $\left\{x_{n}\right\}$ dikatakan Cauchy jika berlaku $\left|x_{n}-x_{m}\right|<\varepsilon$ untuk setiap $\varepsilon>0$. Jika $n \rightarrow \infty$ dan karena $0 \leq p<1$, maka $\frac{2^{p} \theta}{2}\left(\|x\|^{p}\right) \sum_{k=n}^{m-1} \frac{2^{k p}}{2^{k}}=0$. Oleh karena itu, $\lim _{n \rightarrow \infty}\left\|\frac{1}{2^{n}} f\left(2^{n} x\right)-\frac{1}{2^{m}} f\left(2^{m} x\right)\right\|=0$, sehingga dapat dikatakan bahwa $\left\{\frac{f\left(2^{n} x\right)}{2^{n}}\right\}_{n=1}^{\infty}$ merupakan barisan Cauchy untuk setiap $x \in E_{1}$. Karena $E_{1}$ merupakan ruang Banach, dimana setiap barisan Cauchy-nya konvergen, maka terdapat fungsi $A: E_{1} \rightarrow E_{2}$ yang didefinisikan dengan $A(x)=\lim _{n \rightarrow \infty} \frac{f\left(2^{n} x\right)}{2^{n}}$ untuk setiap $x \in E_{1}$.

Selanjutnya akan ditunjukkan bahwa fungsi $A: E_{1} \rightarrow$ $E_{2}$ merupakan fungsi additive.

Pandang bahwa

$$
\begin{aligned}
& \|A(x+y)-A(x)-A(y)\| \\
& =\left\|\lim _{n \rightarrow \infty}\left\{\frac{2 f\left(\frac{2^{n}(x+y)}{2}\right)}{2^{n}}-\frac{f\left(2^{n} x\right)}{2^{n}}-\frac{f\left(2^{n} y\right)}{2^{n}}\right\}\right\| \\
& =\left\|\lim _{n \rightarrow \infty} \frac{1}{2^{n}}\left\{2 f\left(\frac{2^{n}(x+y)}{2}\right)-f\left(2^{n} x\right)-f\left(2^{n} y\right)\right\}\right\| \\
& =\lim _{n \rightarrow \infty} \frac{1}{2^{n}}\left\|\left\{2 f\left(\frac{2^{n}(x+y)}{2}\right)-f\left(2^{n} x\right)-f\left(2^{n} y\right)\right\}\right\| .
\end{aligned}
$$

Dengan menggunakan pertidaksamaan (1), maka didapatkan

$$
\begin{aligned}
\|A(x+y)-A(x)-A(y)\| & \leq \lim _{n \rightarrow \infty} \frac{\theta\left(\|x\|^{p}+\|y\|^{p}\right)}{2^{n}} \\
& =0 .
\end{aligned}
$$

Jadi

$$
\|A(x+y)-A(x)-A(y)\| \leq 0 .
$$

Berdasarkan sifat pertama pada ruang bernorma dan

maka didapatkan

$$
\|A(x+y)-A(x)-A(y)\| \leq 0,
$$

$$
\|A(x+y)-A(x)-A(y)\|=0 .
$$

Berdasarkan sifat kedua pada ruang bernorma, maka didapatkan 


$$
\begin{gathered}
A(x+y)-A(x)-A(y)=0 \\
A(x+y)=A(x)+A(y) .
\end{gathered}
$$

Dari definisi fungsi addditive, maka dapat ditunjukkan bahwa $A: E_{1} \rightarrow E_{2}$ merupakan fungsi additive.

Selanjutnya akan ditunjukkan bahwa A memenuhi

$$
\begin{aligned}
& \| f(x)-A(x)\left\|\leq \frac{2 \theta}{2-2^{p}}\right\| x \|^{p}, \forall x \in E_{1} . \\
&\|f(x)-A(x)\|=\lim _{n \rightarrow \infty}\left\|\frac{1}{2^{0}} f\left(2^{0} x\right)-\frac{1}{2^{n}} f\left(2^{n} x\right)\right\| \\
& \leq \lim _{n \rightarrow \infty} \frac{2^{p} \theta}{2}\left(\|x\|^{p}\right) \sum_{k=0}^{n-1} \frac{2^{k p}}{2^{k}} \\
&=\frac{2^{p} \theta}{2}\left(\|x\|^{p}\right) \lim _{n \rightarrow \infty} \sum_{k=0}^{n-1} 2^{(p-1) k} \\
&=\frac{2^{p} \theta}{2}\left(\|x\|^{p}\right) \lim _{n \rightarrow \infty} \sum_{k=0}^{n-1} \frac{1}{2^{(1-p) k}} \\
&=\frac{2^{p} \theta}{2}\left(\|x\|^{p}\right) \lim _{n \rightarrow \infty}\left(1+\sum_{k=1}^{n-1} \frac{1}{2^{(1-p) k}}\right) \\
&=\frac{2^{p} \theta}{2}\left(\|x\|^{p}\right) \lim _{n \rightarrow \infty}\left(1+\frac{1}{2^{(1-p)}}\right) \\
&=\frac{2^{p} \theta}{2}\left(\|x\|^{p}\right) \lim _{n \rightarrow \infty}\left(1+\frac{1}{2^{(1-p)}}\right) \\
&=\frac{2^{p} \theta}{2}\left(\|x\|^{p}\right) \lim _{n \rightarrow \infty}\left(1+\frac{1}{2^{(1-p)}-1}\right) \\
&=\frac{2^{p} \theta}{2}\left(\|x\|^{p}\right) \lim _{n \rightarrow \infty}\left(\frac{2^{(1-p)}-1}{2^{(1-p)}-1}\right) \\
&=\frac{2^{p} \theta}{2}\left(\|x\|^{p}\right)\left(\frac{2^{(1-p)}-1}{2^{(1-p)}-1}\right) \\
&=\frac{2 \theta}{2\left(2^{(1-p)}-1\right)}\left(\|x\|^{p}\right) \\
&=\frac{\theta}{\left(\frac{2}{2^{p}}-1\right)}\left(\|x\|^{p}\right) \\
&\left.\frac{2^{p} \theta}{2-2^{p}}\right) \\
&\left(\|x\|^{p}\right)
\end{aligned}
$$

Jadi,

$$
\|f(x)-A(x)\| \leq \frac{2^{p} \theta}{2-2^{p}}\left(\|x\|^{p}\right) .
$$

Karena $2^{p}<2, \forall p \in[0,1)$, maka

$$
\|f(x)-A(x)\| \leq \frac{2 \theta}{2-2^{p}}\left(\|x\|^{p}\right) .
$$

Terbukti $\| f(x)-A$. $(x)\left\|\leq \frac{2 \theta}{2-2^{p}}\right\| x \|^{p}, \forall x \in E_{1}$.

Selanjutnya akan ditunjukkan bahwa $A$ tunggal. Andaikan $A$ tidak tunggal, maka akan ada fungsi additive yang lain $B: E_{1} \rightarrow E_{2}$ sedemikian hingga

$$
\begin{aligned}
& \|f(x)-B(x)\| \leq\|f(x)-A(x)\| \leq \frac{2 \theta}{2-2^{p}}\|x\|^{p} \\
& \forall x \in E_{1} \text {. } \\
& \|A(x)-B(x)\|
\end{aligned}
$$

$$
\begin{aligned}
& =\| A(x)-f(x)+f(x-B(x) \| \\
& \leq\|A(x)-f(x)\|+\|f(x)-B(x)\| \\
& =\|f(x)-A(x)\|+\|f(x)-B(x)\| \\
& \leq \frac{2 \theta}{2-2^{p}}\|x\|^{p}+\frac{2 \theta}{2-2^{p}}\|x\|^{p} .
\end{aligned}
$$

Jadi,

$$
\begin{aligned}
\| A(x)- & B(x)\left\|\leq \frac{4 \theta}{2-2^{p}}\right\| x \|^{p} . \\
\|A(x)-B(x)\| & =\lim _{n \rightarrow \infty}\left\|\frac{1}{2^{n}} A\left(2^{n} x\right)-\frac{1}{2^{n}} B\left(2^{n} x\right)\right\| \\
& =\lim _{n \rightarrow \infty} \frac{1}{2^{n}}\left\|A\left(2^{n} x\right)-B\left(2^{n} x\right)\right\| \\
& \leq \lim _{n \rightarrow \infty} \frac{1}{2^{n}} \frac{4 \theta}{2-2^{p}}\|x\|^{p} \\
\ldots \text { Kareñ } & =\frac{4 \theta}{2 p-2^{1}}\|x\|^{p} \lim _{n \rightarrow \infty} \frac{1}{2^{n}} \\
& =0
\end{aligned}
$$

dimana $n \in \mathbb{R}$.

Karena $\quad$... Karena $p<1$

$$
\|A(x)-B(x)\| \leq 0
$$

dan berdasarkan sifat pertama pada ruang bernorma, maka

$$
A(x)=B(x), \forall x \in E_{1} .
$$

Jadi terbukti bahwa $A$ tunggal dan pembuktian teorema Hyers-Ulam-Rassias di atas telah lengkap, sehingga terbukti bahwa persamaan Jensen tersebut stabil.

\section{KESIMPULAN}

Pada artikel ini telah ditunjukkan bahwa persamaan fungsional Jensen telah memenuhiteorema kestabilan Hyers-Ulam-Rassias. Oleh karena itu, dapat dikatakan bahwa persamaan fungsional Jensen tersebut stabil. Dengan demikian, persamaan fungsional Jensen ini dapat diaplikasikan sebagai model dari suatu proses fisik.

\section{DAFTAR PUSTAKA}

[1] P. K. Sahoo and P. Kannappan, "Introduction to Functional Equations," in Introduction to Functional Equations, New York, CRC Press, 2011.

[2] R. Coleman, "Calculus on Normed Vector Spaces," London, Springer Science+Business Media New York, 2012.

[3] S. Darmawijaya, "Pengantar Analisis Abstrak," Yogyakarta, Jurusan Matematika Fakultas Matematika dan Ilmu Pengetahuan Alam UGM, 2007.

[4] R. G. Bartle and D. R. Sherbert, "Introduction to Real Analysis," New York, John Wiley \& Sons, Inc., 2000. 
[5] M. Muslikh, "Analisis Real," Malang, Universitas Brawijaya Press, 2012.

[6] R. S. Al-Mosadder, "On Stability of Some Types of Functional Equations," Gaza, Islamic University of Gaza, 2012.

[7] S. M. Jung, "Hyers-Ulam-Rassias Stability of Functional Equations in Nonlinear Analysis," London, Springer Science+Business Media, 2011.

[8] A. G. Parlos, "Linearization of Nonlinear Dynamics," 2014. [Online]. Available: http://parlos.tamu.edu/MEEN651/Lineariz ation.pdf. [Accessed 17 Agustus 2014].

[9] R. C. Robinson, An Introduction Dynamical System Continuous and Discrete, New Jersey: Pearson Education, 2004.

[10] W. E. Boyce and R. C. DiPrima, Elementary Differential Equations and Boundary Value Problems, New York: John Wiley \& Sons, Inc, 2009.

[11] R. O. Kwofie, "A mathematical model of a suspension bridge - case study: Adomi bridge, Atimpoku, Ghana," Global Advanced Research Journal of Engineering, Technology, and Innovation, vol. 1(3), pp. 047-062, 2012.

[12] G. Vries, T. Hillen, M. Lewis, J. Müller and M. Schönfisch, A Course in Mathematical Biology: Quantitative Modeling with Mathematical and Computational Methods, Alberta: SIAM, 2006.

[13] P. K. s. d. P. Kannappan, "Introduction to Functional Equations," in Introduction to Functional Equations, New York, CRC Press, 2011, p. 2. 